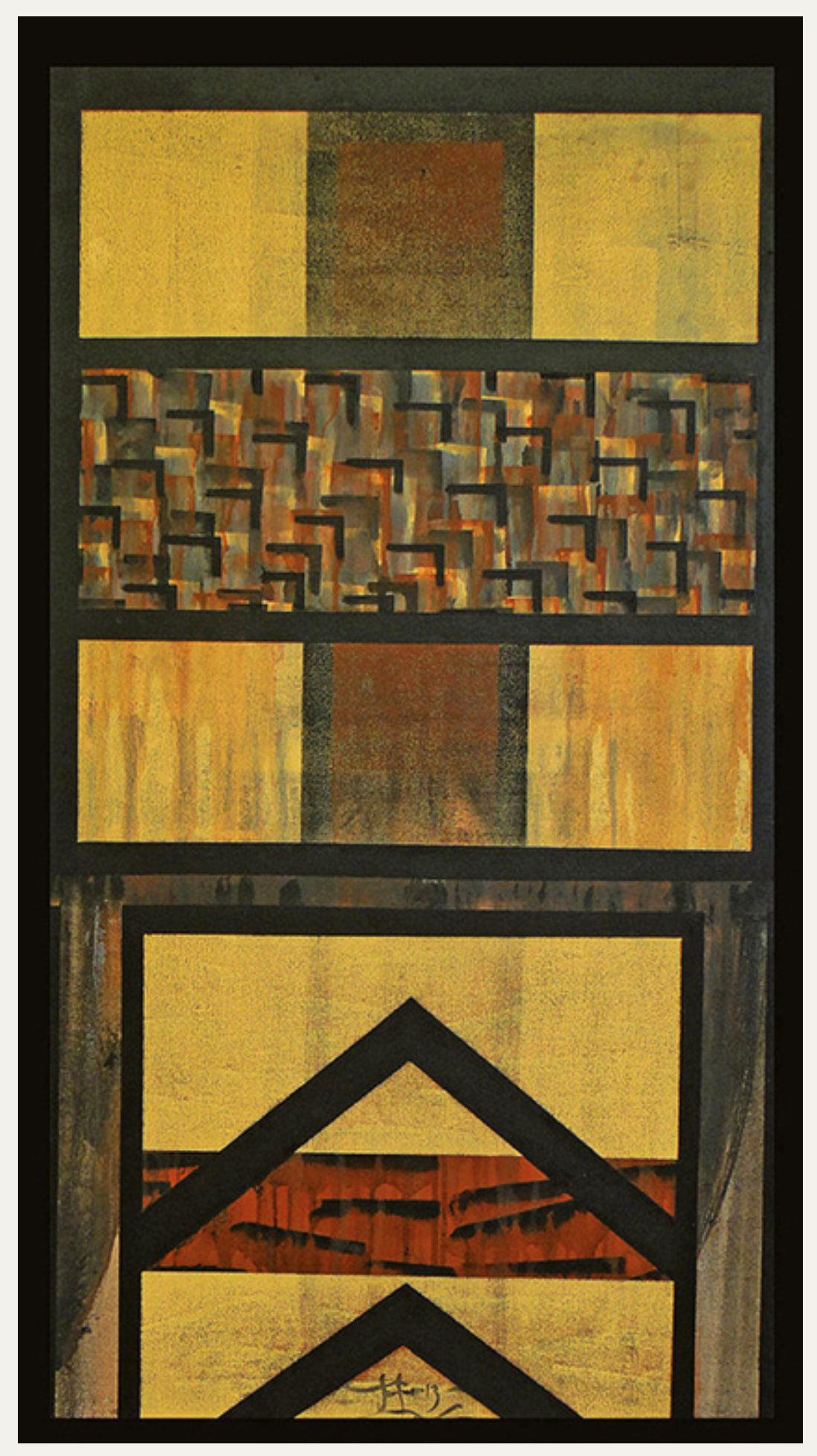

\title{
IA PATABRA
}




\title{
TRAS LOS PASOS,SOBRE LAS HUELLAS IE ANDRÉS GAICEDO
}

\section{Michelle Vázquez Soriano}

E n agosto de 2016 viajé a Colombia siguiendo los pasos de un autor que el azar había puesto en mis manos. Supe de su existencia en 2009 por una nota en La Jornada. El cineasta y escritor chileno Alberto Fuguet había montado una autobiografía de un tal Andrés Caicedo (Cali, 29 de septiembre de 1951-4 de marzo de 1977). Sin éxito busqué sus libros en las librerías mexicanas. Un año después pude al fin conseguir algunos ejemplares en El Ateneo de Buenos Aires. Debo confesar, sin embargo, que el hallazgo de un joven escritor, hermoso y suicida, me contrarió: “¿cómo no había sabido de él antes?”, me preguntaba como lo había hecho Fuguet apenas unos años atrás. “iTan fuerte era el poder de García Márquez en Colombia -continuaba el cineasta-, que terminaba asesinando a un chico urbano por el solo hecho de ser incondicional a Jerry Lewis y estar obsesionado con Kim Novak?” (Fuguet 2009, 11).

Caicedo fue un joven escritor anómalo, por así decirlo -como José Agustín o Gustavo Sainz en México-, que durante los años setenta no cayó en la tentación marxista. Su obra escapa a toda postura política en plena Guerra Fría. Sus historias son relatos de

\begin{abstract}
Caicedo fue un joven escritor anómalo, por así decirlo -como José Agustín o Gustavo Sainz en México-, que durante los años setenta no cayó en la tentación marxista. Su obra escapa a toda postura política en plena Guerra Fría. Sus historias son relatos de iniciación en donde la juventud experimenta por primera vez.
\end{abstract}

iniciación en donde la juventud experimenta por primera vez: la droga, el sexo y las calles de una ciudad penetrada por la psicodelia y los movimientos contraculturales. Sin embargo, es probable que ni el contexto hiperpolitizado en el que escribió, ni la sombra del macondismo sobre los escritores colombianos hayan sido los únicos factores que hicieron de Caicedo por mucho tiempo un autor prácticamente desconocido fuera de sus fronteras nacionales. Su suicidio, me parece, también jugó un papel relevante. Tras su deceso, la familia condenó su habitación con todos sus objetos personales: manuscritos, discos, libros, afiches de cine. Todo permaneció intacto durante años hasta que, a principios de los ochenta, el dramaturgo Sandro Romero Rey tocó a su puerta y se ofreció a organizar su obra.
Los motivos de su suicidio no son claros, pues a pesar de haber fallecido sobre su máquina de escribir, no dejó nota de despedida. De ese día solo sabemos que, por la mañana, había discutido con Patricia Restrepo, su pareja desde hacía dos años, y que antes del mediodía había recibido el primer ejemplar de la que se convertiría en su novela de culto: $i$ Que viva la música! (1977). Cuando Patricia volvió al departamento lo encontró agonizando y respondiendo una misiva a su amigo epistolar, el crítico de cine Miguel Marías. "Andrés sí tomaba Valium", me contaría ella casi cuarenta años después, "pero porque su angustia existencial era muy grande". Durante nuestra conversación insiste en que él no era el drogadicto que muchos han querido ver, sino una persona disciplinada que se 
levantaba todos los días a las siete de la mañana a escribir, pero "para él era difícil soportar su interior", me explica. De ahí los sedantes. Su malestar debió ser sin duda profundo, porque ese día se tomó uno, después otro, o todos a la vez (cómo saberlo), y así hasta que con la ayuda de 60 pastillas de secobarbital logró, al fin, encontrar reposo.

Veinticinco años fueron suficientes para que Caicedo se ganara el reconocimiento de la juventud caleña, y no solo como escritor. "Una cara que siempre me gusta destacar de Andrés", me dice su amigo Ramiro Arbeláez, "es la de promotor cultural”. Caicedo se inició en el teatro, antes de dedicarse por completo al cine y a la literatura. Siendo un bachiller escribió y dirigió obras teatrales, creó el Tesca (Teatro Estudiantil de Cali) y después el grupo teatral de la Universidad del Valle. Además, en 1971 fundó el Cine Club de Cali (de cuya programación se encargaría hasta su muerte) y de 1974 a 1976 publicó la revista Ojo al cine. "Andrés era muy generoso con su conocimiento", me comenta Arbeláez, quien desde sus inicios lo acompañó en sus empresas culturales. Caicedo no tardó en ganar notoriedad en su ciudad, "una ciudad llena de sol, de vida y gente joven", evoca Patricia. Por ello la muerte del autor generaría un profundo vacío entre sus seguidores, incluso para los que apenas lo conocían, como Sandro Romero Rey, quien más tarde, junto al cineasta Luis Ospina, se convertiría en editor de su obra: "Yo no fui muy amigo de Andrés”, me aclara Sandro, "lo conocía de hacerle un par de preguntas a la entrada o a la salida del Cine Club [de Cali] y no más".

Caicedo publicó dos libros mientras vivió: El atravesado (1975) y iQue viva la música! (1977), algunos cuentos e innumerables artículos de críti-
Andrés Caicedo sí publicó en México, tal vez no la novela que deseaba pero sí un cuento: en octubre-diciembre de 1972 apareció en el número 4 de la Segunda Época de La Palabra y el Hombre de la Universidad Veracruzana "El tiempo de la ciénaga".

ca cinematográfica en periódicos colombianos, así como en algunas revistas extranjeras, entre ellas, la peruana Hablemos de cine, o la venezolana Imagen, donde, además, fue galardonado por su cuento "Los dientes de Caperucita" (1969). Pero no fue sino hasta 1984 que su número de lectores se amplió en Colombia, cuando Romero Rey y Ospina publicaron Destinitos fatales en la Editorial Oveja Negra. El libro contenía gran parte de la obra inédita del autor y estaba dividido en: Calicalabozo (selección de cuentos); Angelitos empantanados (o historias para jovencitos) y la novela inconclusa Noche sin fortuna.

Caicedo fue un escritor precoz y tenaz. Si bien su suicidio lo relegó por mucho tiempo a un reducido número de lectores, nunca fue por falta de iniciativa de un autor que, en 1973, había viajado a Estados Unidos con la firme convicción de vender unos guiones cinematográficos a Roger Corman, productor de "serie b" que había impulsado la carrera de importantes directores como Francis Ford Coppola y Martin Scorsese, o de actores como Peter Fonda y Jack Nicholson. Aunque nunca llegó a conocer al productor, los deseos de Caicedo de internacionalizarse siempre estuvieron presentes; ya en 1972 había intentado publicar en México su novela El atravesado.

Durante mi estancia, tanto en Cali como en Bogotá, tuve la oportunidad de conocer a Rosario, Pilar y María Victoria Caicedo, hermanas del autor, quienes me autorizaron a consultar el vasto archivo de su obra, el cual no solo contiene manuscritos sino también facturas, actas, recibos, recortes de periódicos, cartas y, para mi asombro, la prueba de que Andrés Caicedo sí publicó en México, tal vez no la novela que deseaba pero sí un cuento: en octubre-diciembre de 1972 apareció en el número 4 de la Segunda Época de La Palabra y el Hombre de la Universidad Veracruzana "El tiempo de la ciénaga". El relato había ganado, según un documento encontrado, el primer lugar en el Concurso de Cuento de la Universidad Externado de Colombia. El fallo lo dio el escritor venezolano Luis Britto García, el 1 de agosto de ese mismo año.

Caicedo era un gran admirador de Herman Melville; no por nada el seudónimo con el que presentó su relato fue Ismael Muñoz. "El tiempo de la ciénaga" trata de una pareja de niños bien del norte de Cali que intentan escapar del tedio que les produce su clase social viendo películas y leyendo: "leímos todo Melville y aprendimos a temer al mar" $(1972,26)$. Pero "de tanto leer poesía y de tanto ver cine nos fuimos volviendo muy progresistas" (26), dice el narrador. Así, un día tomaron un autobús para ir a un cine de segunda, en los barrios pobres del sur. Britto García señala en su veredicto que este relato describe la desigualdad social y el fracaso de la cultura libresca para entablar 
vínculos humanos, por lo que el humor negro se transforma en un componente decisivo: "les hablé de Herman Melville y de libros bien famosos, pero ¿cómo hacía si ellos nunca habían oído hablar de eso?" (28). Como en todos los relatos de Caicedo, la historia no resuelve ningún conflicto social; el autor se contenta con mostrar el resentimiento de unos y, como lo señala Britto García, el ingenuo esnobismo de los otros. Los protagonistas mueren (ella a navajazos, él a golpes) en manos de unos chicos del sur: "mi error -dice el narrador ante la fatalidad ineludible - fue utilizar términos complicados porque creyeron que lo que estaba hablando era literatura" (33).

En el archivo de la familia también existe una carta membretada y firmada por el escritor mexicano Emilio Carballido, quien por esa época formaba parte del comité de redacción de $\mathrm{LaPa}$ labra y el Hombre. Un 28 de agosto -deduzco de 1972-, Carballido le mandaba a Caicedo la dirección de la Editorial de la uv para que publicara su cuento galardonado, $y$ la de la editorial mexicana Novaro. Entre los documentos encontrados también aparece un contrato con dicha editorial, bajo la dirección de Luis Guillermo Piazza, y con fecha del 7 de junio de 1972, para la publicación de la novela $E l$ atravesado. Sin embargo, por lo que escribe Carballido, la editorial perdería el manuscrito, aunque le aconseja al joven escritor no retirarles los derechos de publicación, ya que cada seis meses solían pagar buenas regalías. Carballido se despide diciendo que pronto partiría a Europa, por lo que seguramente ya no leería su respuesta. Sin embargo, lo anima a seguir escribiendo y a no dejar de enviarle nuevos textos cuando pueda.

Romero Rey me explicará después en una conversación telefóni-

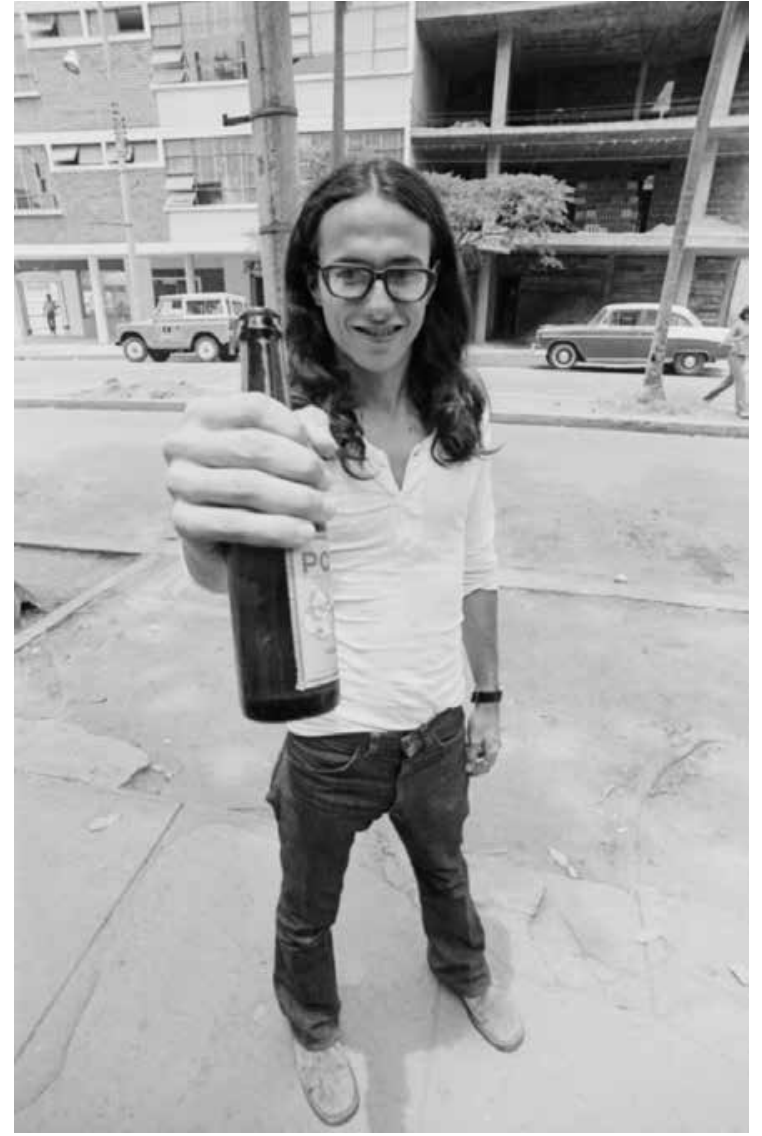

Andrés Caicedo. Fotografía de Eduardo La Rata Carvajal.

ca que sería Britto García quien, al parecer, ayudaría a Caicedo en su búsqueda de editor en México. De hecho, en una carta sin fecha, el autor de Rajatabla también le había mandado la dirección de El Cuento, revista mexicana dirigida por su amigo Edmundo Valadés, para que enviara su relato "Maternidad", pero el texto, por razones que ignoro, no se publicaría. En la misma misiva le manda también la dirección de la editorial argentina Crisis, dirigida por Eduardo Galeano, para que enviara el manuscrito de $; Q u e$ viva la música!, pero la novela no sería publicada sino en 1977 por Juan Gustavo Cobo Borda en Colcultura.

Uno de los problemas para seguirle la pista a este autor, discuto con Romero Rey, es que mucho material suyo se perdió, como la primera versión de $; Q u e$ viva la música!, que inicialmente era un cuento de 90 páginas, sin contar los muchos artículos que tampoco llegaron a destino. Reconstruir su trayectoria, entonces, no es tarea fácil. El atravesado, finalmente, se publicaría tres años después (1975) en Cali, en Ediciones Pirata de Calidad, publicación un tanto casera financiada por Nellie Estela, madre del autor. En esta novela corta, el narrador es un pandillero que rememora los tiempos de la Tropa Brava, gallada caleña, en la que aprendió a pelear y a ser el terror de los demás.

Cali está presente en toda la obra de Caicedo, y aunque la ciudad de sus relatos ya no existe, algo perdura en su clima y sus paisajes. Por eso su visita es ineludible. Eduardo La Rata Carvajal, amigo de Andrés, me cuenta orgulloso que también fue pandillero mientras caminamos por la ciudad. Eduardo y Andrés se 
conocieron en el 72, en Ciudad Solar, centro cultural alternativo fundado en 1971 por Hernando Guerrero. Carvajal fue el fotógrafo que inmortalizó la imagen del joven escritor, sus fotografías han sido utilizadas para muchas de sus portadas. También realizó la foto fija de la película inconclusa de Caicedo y Carlos Mayolo: Angelita y Miguel Ángel. ${ }^{1}$ Carvajal me guía y me muestra, entre otros sitios, lo que sobrevive del Colegio San Juan Berchmans y de la fuente de sodas Deiri Frost, lugares emblemáticos de los personajes caicedianos. Y siguiendo por la legendaria Avenida Sexta, llegamos al edificio Cordiki, donde un portero nos mira desconfiado porque ya conoce el cuento y sabe que no queremos rentar el departamento que está anunciado, sino husmear, echar un vistazo a lo que queda del inmueble donde un joven escritor acabó con su vida.

Ishmael, el narrador de Moby Dick, dice que para escapar del tedio va al mar, su sustituto for pistol and ball. Caicedo, en cambio, escribía sobre el mar hasta que ya nada pudo sustituir a la muerte. La obra de Caicedo fascina por el contraste entre la vitalidad de sus relatos y el misterio que la envuelve: los motivos de su suicidio, así como la desaparición de personas que podrían aclararnos aspectos de su obra. Sabido es que Caicedo se mató el mismo día que recibió el primer ejemplar de $i$ Que viva la música!, pero no todos saben que por esas mismas fechas, en mayo de 1977, se publicó en Medellín por primera vez Angelitos empantanados (o historias para jovencitos), en la editorial La Carreta. Romero Rey me aclara que Andrés había trabajado en esa edición con Roberto Fernández, el diseñador de la portada. Sin embargo, la infor-

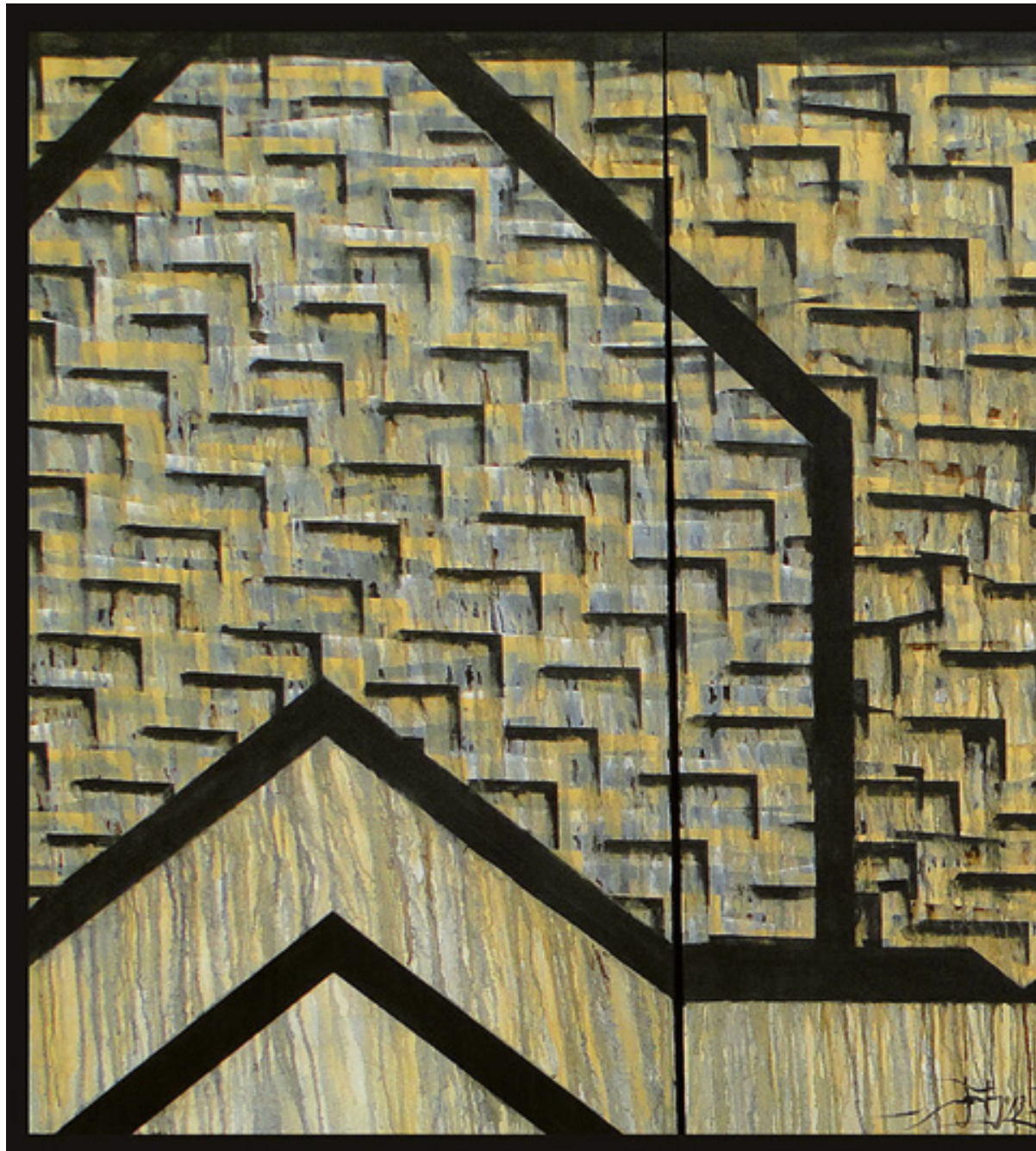

Caicedo fascina por el contraste entre la vitalidad de sus relatos y el misterio que la envuelve: los motivos de su suicidio, así como la desaparición de personas que podrían aclararnos aspectos de su obra. mación sobre esa publicación es escasa ya que, al parecer, los que estuvieron a cargo de la impresión también se suicidaron. Como Fernández, me dice Romero Rey, que se ahorcaría en Medellín.

En la dedicatoria de su libro Memorias de una cinefilia (2015), me escribe Sandro: "Después de ir tras los pasos, sobre las huellas de Caicedo, en un paisaje que no fue el suyo..." Cierto, Cali ya no es la misma ciudad que el autor recorrió, pero algo persiste en la memoria de unos y en los manuscritos de un escritor 


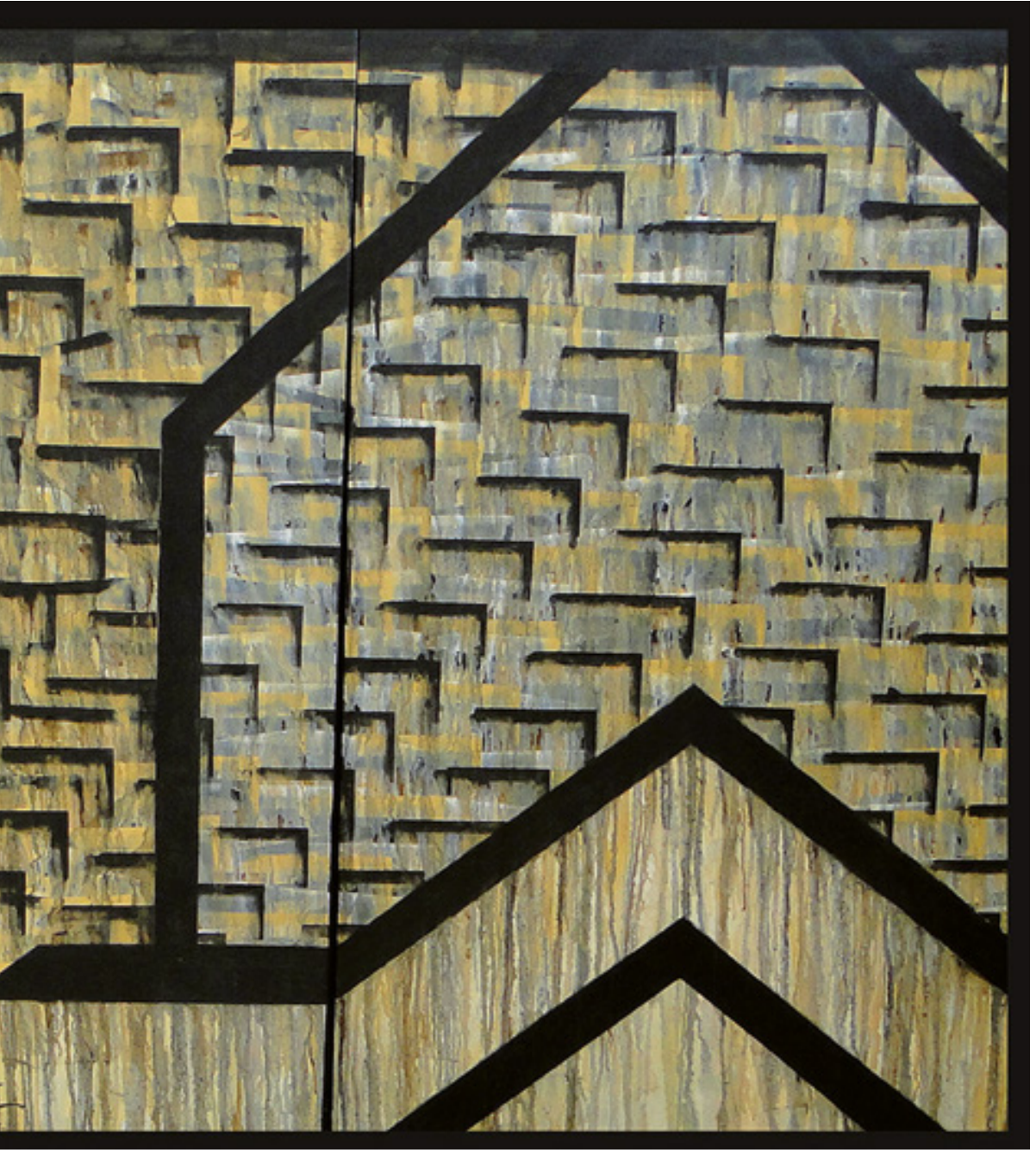

Señal árbol (tríptico)

que hizo de Cali una fuente de creación y de destrucción. Caicedo escribe: "Ciudad de mierda esta, Calicalabozo, se está y se quiere ir, se va y se quiere estar", $(2008,151)$. Andrés soñaba con abandonar la ciudad que lo atraía, a veces, con una inercia negativa: "hermano -escribe en julio de 1974 a su amigo Luis Ospina, quien estaba en París-, háceme el favor y me informas exactamente cuál es tu situación legal allá en Francia (visa, etc.)” (151). No iría a Francia, pero con grata sorpresa descubro que, entre sus escapadas,
No lo podemos negar: la presencia de Caicedo en México fue circunstancial, cuando no fallida. Quizás su única publicación en nuestro país haya sido la de La Palabra y el Hombre.

anduvo en nuestro país: “También estuve en México, en Laredo, un pueblo fronterizo" (78).

No lo podemos negar: la presencia de Caicedo en México fue circunstancial, cuando no fallida. Quizás su única publicación en nuestro país haya sido la de $L a$ Palabra y el Hombre, pero esa accidentada huella bastó para que nosotros, sus nuevos lectores, le sigamos la pista tratando de reconstruir el imposible rompecabezas de un joven escritor obsesionado con la muerte, y de paso, tal vez, también saldar una deuda con nuestra juventud, porque la obra genial de Andrés Caicedo, por los motivos que hayan sido, nos llegó tarde y ya no tuvimos tiempo de convertirla en ese sustituto cuando el tedio nos invitaba al mar. LPyH

\section{REFERENCIAS}

Caicedo, Andrés. 1972. "El tiempo de la ciénaga”. La Palabra y el Hombre 4: 23-33.

-.2008. Mi cuerpo es una celda (una autobiografía). Selección por Alberto Fuguet. Bogotá: Alfaguara.

-.2009. Noche sin fortuna. Prólogo: "Andrés más Caicedo: dos encuentros" por Alberto Fuguet. Bogotá: Norma.

Nota

${ }^{1}$ Luis Ospina, a quien tuve la oportunidad de entrevistar en el Festival des 3 Continents de Nantes (2014), recuperó esas imágenes en su documental Andrés Caicedo: unos pocos buenos amigos (1986).

Michelle Vázquez Soriano es licenciada en Sociología (Uv) y maestra en Literatura Francesa y Comparada por la Universidad de Nantes (Francia), donde actualmente trabaja y consagra una tesis doctoral al escritor colombiano Andrés Caicedo. 